\title{
DEÍXIS Y PRONOMBRE. CONSIDERACIONES EN TORNO AL ORIGEN DEL CONCEPTO DE DEÍXIS'
}

\author{
María Muñoz Romero
}

\begin{abstract}
Even though the function of deixis is not limited to any particular word classes, since it can actually be expressed through very diverse morphosyntactic categories, the fact is that until quite recently the concept of deixis has been only limited to pronouns. Both the origine of the term and the phenomenon associated with it, have actually been closely linked to the grammatical theory of pronouns. In order to show how the concept of the term has envolved, we have adopted a historic perspective to describe the successive stages in the elaboration of the concept of deixis, which have preceded the recent developments in contemporary linguistics.
\end{abstract}

\section{INTRODUCCIÓN}

El título dado a este trabajo parece sugerir una limitación con respecto a las teorías más recientes sobre la deíxis, en las que la categoría de deíctico constituye una categoría mucho más amplia que la de pronombre. Así, P. Carbonero, en su Deíxis espacial y temporal en el sistema linguístico (1975:15), aclara que el término pronombre "recoge una clase de palabras de determinado comportamiento morfosintáctico (...), mientras que el término deíctico se adhiere a un funcionamiento lingǘstico general, de un nivel más alto, consistente en establecer una relación directa con la situación, el contexto y la interlocución, en un plano mostrativo". Los pronombres constituirían, por tanto, tan sólo un subsistema del fenómeno general de la deíxis.

En efecto, la función deíctica no es privativa de una clase de palabras. La deíxis puede ser expresada por categorías morfosintácticas muy diversas: no sólo por pronombres, como je, tu, celui-ci, cela, le mien, etc., sino también por adverbios y locuciones adverbiales, como aujourd'hui, demain, hier, ici, là, dans trois jours, il y deux ans, etc.; por verbos, como aller/venir; por morfemas verbales, como el morfema de persona o el de actualidad, que añadido al de época, sitúa el proceso verbal en un pasado, presente o futuro con respecto al momento de enunciación; por determinantes, como $c e(t)$, mon, ton, etc. o el propio artículo, que en muchos de sus usos funciona como deíctico, obligándonos a remitirnos a la situación de enunciación para poder identificar la persona o el objeto referidos (ej. "Donne-moi le crayon", acompañado de un gesto o de una mirada hacia el objeto en cuestión); etc.

\footnotetext{
${ }^{1}$ Estudio aplicado a la lengua francesa.
} 
Entonces, ¿por qué este título que parece identificar deíxis con pronombre? En realidad, se trata de una precisión impuesta por la observación de los hechos, ya que hasta fecha relativamente reciente, el concepto de deíxis se ha visto subordinado al de pronombre. Como bien dice R. Escavy (1987:126), "tanto el origen del término como el del fenómeno designado por él dentro de la investigación lingüística están íntimamente ligados a la teoría gramatical sobre el pronombre". En efecto, la teoría de los pronombres es la que sirve inicialmente de marco al concepto de deíxis ${ }^{2}$.

Así pues, siguiendo de cerca las transformaciones que han afectado a este sector de la investigación gramatical, intentaremos mostrar cómo se ha constituido el concepto sobre el que gira el presente trabajo. Nos proponemos, por tanto, evocar aquí un panorama histórico que nos permita trazar las etapas sucesivas de la constitución del concepto de deíxis que preceden a las transformaciones e innovaciones que, en torno a esta noción, tendrán lugar en el marco de la lingüística contemporánea.

\section{LA TRADICIÓN GRECOLATINA}

Comenzaremos este recorrido histórico por la figura de Prisciano, considerado por muchos como el representante más importante de la tradición grecolatina ${ }^{3}$. Sin embargo, no hemos elegido a este autor por la originalidad de su pensamiento, ni porque pensemos que sea el más interesante de los gramáticos de esta época, sino porque su obra resume el pensamiento gramatical de la Antigüedad, desde el advenimiento de la gramática griega hasta el siglo VI de nuestra era. Por otra parte, su obra, junto con la de Donato (s. IV d.C.), ha ejercido una profunda y duradera influencia sobre la reflexión teórica de la Edad Media y del Renacimiento.

La definición de Prisciano de las tres personas gramaticales sorprende por su precisión, pero desconcierta por el papel tan secundario que desempeñan en la caracterización de los pronombres. La primera persona es definida como la que utiliza la persona que habla para hablar de sí misma. La segunda como la que esta misma persona emplea para hablar de la persona a la que dirige la palabra. La tercera como la que utiliza la persona que habla para referirse a una persona que no es ni la que habla ni a la que se habla (Prisciano, libro XII, cap. $3, \S 13$; Keil, t.II, p.584). Prisciano se preocupa de explicar la necesidad de esta enrevesada definición, insistiendo en que no podemos limitarnos a decir que la primera persona es la que habla, la segunda a la que se habla y la tercera de la que se habla, ya que puede ocurrir, por ejemplo, que la persona que habla no diga nada sobre sí misma, y, por consiguiente, esta

\footnotetext{
${ }^{2}$ Sin embargo, merece la pena señalar que en la tradición griega los deícticos -adjetivo derivado del verbo deiknymi ("mostrar", "señalar") y que fue traducido por los latinos con el término demostrativus- eran considerados artículos y no pronombres. La palabra arthron -de cuya traducción latina proviene el término artículo- significaba "articulación, unión" y, en efecto, en griego antiguo el carácter de dependencia del contexto y de conexión de estas unidades primaba sobre el criterio funcional que más tarde motivó la nueva denominación de pronombres. El término artículo se aplicaba tanto a los demostrativos, como al artículo o al relativo, ya que todos ellos eran considerados como conectores de diversos tipos.

${ }^{3}$ Las obras de Prisciano fueron recogidas bajo el título de Institutiones Grammaticae, que consta de 18 libros, distribuidos durante la Edad Media en dos volúmenes. El primero contenía los 15 primeros libros, y el segundo los tres últimos, que eran realmente una traducción de la Sintaxis de Apolonio Díscolo.
} 
definición sería insuficiente ${ }^{4}$. Estas precauciones parecen indicar que Prisciano había intuido el vínculo que une la noción de persona a la de acto de habla, y, sin embargo, su reflexión sobre este punto no va más allá. El concepto de enunciación no aparece jamás de manera explícita.

El concepto de persona, definido con tanta precisión, desempeña sin embargo, como ya hemos dicho, un papel accesorio en la definición de los pronombres. La persona era concebida exclusivamente como un accidente de la significación fundamental de los pronombres, como una especie de flexión comparable a la declinación casual (Prisciano, libro XVII, cap.8, § 54; Keil, t.III, p.140). Para Prisciano, como para sus predecesores, lo importante era trazar la frontera entre nombre y pronombre. Según Prisciano, el nombre se diferencia del pronombre por el hecho de remitir a una sustancia asociada a una cualidad, mientras que el pronombre excluye la representación de toda cualidad. El pronombre expresa la noción abstracta de sustancia y tiene la propiedad de designar a un individuo o a una cosa sin hacer referencia a las cualidades que permiten identificarlo (Prisciano, libro II, cap. 4 , § 18; Keil, t.II, p.55; y libro XII, cap. 3, § 15; Keil, t.II, pp.585-586).

Para Prisciano, todos los pronombres son definidos, rasgo que les es conferido ya sea por demonstratio, ya sea por relatio. Un pronombre es demostrativo cuando designa un objeto que no ha sido aún mencionado en el discurso, y relativo cuando se aplica a un objeto al que ya se ha aludido (Prisciano, libro XII, cap. 1, § 4; Keil, t.II, p.579).

Prisciano clasifica los pronombres en tres categorías: a) los pronombres que expresan únicamente una demonstratio ad oculos (EGO, TU); b) los que se prestan tanto a la demonstratio ad oculos como a la demonstratio ad intellectum (HIC, ISTE, ILLE); y c) los relativos (IPSE, IS). Y añade que el valor demostrativo de HIC, ISTE e ILLE se dirige al "espíritu" ("ad intellectum") cuando remiten a algo que no está presente (Prisciano, libro XVII, cap.9, § 57; Keil, t.III, p.142).

En cuanto a la noción de demonstratio, nos parece interesante subrayar el carácter abstracto que tiene en Prisciano. En ningún momento se hace referencia a la intervención de un gesto en el funcionamiento de la mostración. Ello explica que los pronombres personales se hallen incluidos en esta categoría junto a términos como HIC o ISTE. Da la impresión de que estos elementos han sido agrupados en una clase única por su aptitud común para designar a un ser presente en la situación concreta del acto de comunicación.

En lo que se refiere al concepto de demonstratio ad intellectum, su función es garantizar la distinción entre los auténticos demostrativos como HIC, ISTE, ILLE, y los anafóricos puros como IS, incluso en los casos en que parecen funcionar de la misma manera.

Otro rasgo fundamental de la caracterización de los pronombres de Prisciano es la equivalencia que establece entre éstos y los nombres propios. Ello le permite excluir de la clase de los pronombres signos como QUIS, QUI, TALIS, TANTUS, que, según él, son nombres comunes porque expresan la vaga noción de sustancia asociada a la idea muy general de cualidad (Prisciano, libro II, cap. 4, § 18; Keil, t.II, p.55).

\footnotetext{
${ }^{4}$ Prisciano se refería posiblemente a la definición de Varrón: "cum item personarum natura triplex esset, qui loqueretur, ad quem, de quo: haec ab eodem verbo declinata" (libro VIII, § 20; Heinemann, vol.II, p.386).
} 
En cuanto a las personas de la comunicación, Prisciano observa que para las dos primeras no hay más que un pronombre, mientras que para la tercera existen varios. Esta diferencia se explicaría, según él, por el hecho de que la primera y la segunda están siempre presentes la una para la otra, de manera que un único pronombre -demostrativo, en su terminología- es suficiente para cada una de ellas. Sin embargo, lo que se designa mediante la tercera persona no está necesariamente presente, y ésta sería la causa de la diversidad de pronombres que le corresponden (Prisciano, libro XII, cap. 1, § 1; Keil, t.II, p.577).

Como vemos, aunque para Prisciano EGO y TU son siempre demostrativos, no queda nada claro que atribuya este valor a la naturaleza del papel que desempeñan las personas designadas por ellos. Mientras que, para nosotros, el valor demostrativo o deíctico de estos pronombres es absolutamente indisociable del contenido mismo de los conceptos de primera y segunda persona, en Prisciano este vínculo no está claramente expresado. Se limita a decir que EGO y TU son demostrativos porque designan personas siempre presentes (Prisciano, libro XII, cap. I, § 3; Keil, t.II, p.578).

Las ideas de Prisciano serían fielmente seguidas por los teóricos de la Edad Media que, situándose en un nivel muy abstracto, no aportan nada nuevo a la descripción. Sus reflexiones giran en torno a las relaciones del lenguaje con el funcionamiento de la mente, y no sobre el lenguaje considerado en sí mismo. Esta es la razón principal del considerable empobrecimiento del material lingüístico utilizado, en comparación con la profusión de datos concretos que encontramos en las gramáticas de la Antigüedad.

En el Renacimiento, hallamos una importante innovación en lo que se refiere a la definición del signo lingüístico. Los gramáticos renacentistas consideran a los signos como marcas "puestas sobre las cosas" (Cfr. Sánchez de las Brozas 1587: libro I, cap.1). Esto permite comprender en qué términos se plantea la cuestión de la naturaleza de los pronombres. Al definir los nombres como las marcas de las cosas (NOTAE RERUM), caben dos maneras de considerar los pronombres: a) como marcas de segundo grado, que serían histórica y lógicamente posteriores a los nombres, o b) como las marcas primitivas, de las que se servían los hombres cuando aún no existían los nombres, o, por lo menos, cuando no se disponía aún de suficientes nombres para designar todas las cosas.

Si elegimos la primera posibilidad, estamos valorando un solo aspecto de la definición de Ios antiguos (PRONOMEN EST PARS ORATIONIS QUAE PRO NOMINE PONITUR), y reduciendo el pronombre a la categoría de simple representante del nombre (NOMEN VICARIUM). Ciertos gramáticos renacentistas como Escalígero o El Brocense rechazan esta interpretación y retienen la segunda solución. Términos como HOC o ILLUM serían los signos de que se servían los hombres para designar las cosas que no habían recibido aún un nombre. Por tanto, convendría denominarlos prima nomina en vez de pronomina (Cfr. Escalígero, libro VI, cap. CXXVII, pp.255-57; Sánchez de las Brozas, libro I, cap. 2).

Por otra parte, se asigna a los demostrativos un estatus particular. Se sostiene que cuando se trata de designar a un ser que está presente, los pronombres demostrativos son más eficaces que los nombres y evitan ambigüedades. A pesar de ello, no se produce renovación alguna en la reflexión sobre el concepto de mostración que se mantiene más o menos como en Prisciano. Sin embargo, sí que encontramos un tratamiento interesante de la noción de 
relación en la obra del Brocense. Este gramático toma deliberadamente al pie de la letra la fórmula anteriormente mencionada (NOMEN EST PARS ORATIONIS...) y observa que puede decirse Poeta por Virgilio, Dux por Pompeyo, Orator por Cicerón, y que, por consiguiente, los sustantivos utilizados en lugar de nombres propios deberían ser considerados como pronombres (Sánchez de las Brozas, libro I, cap. 2). Ello le sirve como argumento para demostrar que la definición tradicional del pronombre es inaceptable, ya que esta clase se confunde con la de los nombres.

Así pues, si bien es cierto que en los gramáticos del Renacimiento encontramos el terreno de la observación concreta que faltó en la Edad Media, su trabajo no aportó verdaderamente nada nuevo en lo que a los pronombres se refiere. Hay, ciertamente, observaciones interesantes, pero ningún cambio sustancial en los conceptos heredados de los gramáticos de la Antigüedad. Es preciso llegar a la Época Clásica para asistir a una profunda renovación en la definición de los pronombres, al recurrirse al concepto de acto de habla.

Cabe preguntarse qué fue lo que obstaculizó durante tanto tiempo un enfoque que hoy día nos parece tan evidente. Es difícil dar una respuesta definitiva, pero podríamos aventurar la hipótesis de que todo fue debido al lugar que se le asignaba a la gramática en el conjunto de las disciplinas relacionadas con el lenguaje. Hasta el comienzo de la Época Clásica, el campo de la gramática se encontraba limitado por el de la retórica. La tarea de un gramático consistía en describir la flexión de las palabras y lạs reglas de ordenación sintáctica, pero nunca en interrogarse sobre el lenguaje en uso. La gramática se limitaba a enunciar las reglas que debían respetarse para que la frase estuviera bien construida, pero su competencia no llegaba hasta el acto mismo de la enunciación.

Sin embargo, en el siglo XVIII las cosas cambian, probablemente a causa del declive de la antigua retórica. Como cabe suponer, los gramáticos se apresuraron a conquistar el terreno hasta entonces ocupado por ésta, y ello los llevó a explorar espectos del lenguaje que antes no les competía. Y así, en la segunda mitad del siglo XVIII, aparece por primera vez el concepto de enunciación.

\section{LA ÉPOCA CLÁSICA: LA GRAMMAIRE GÉNÉRALE DE BEAUZÉE. CREACIÓN DEL CONCEPTO DE "ACTE DE LA PAROLE".}

Generalmente, se hace coincidir el comienzo de la Época Clásica con la publicación de la Grammaire générale et raisonnée de Arnauld y Lancelot en 1660. La innovación fundamental de estos autores es el lugar central asignado a la noción de proposición concebida como la expresión de un juicio (Arnauld/Lancelot 1969 (1660): 23). El acto de juzgar es considerado como la operación más eminente del espíritu y el lenguaje comienza verdaderamente con la expresión de dicho acto. Por tanto, el objeto de la gramática no es ya el producto del discurso, sino su realización: una operación y no el resultado de ella.

A pesar de estas innovaciones, estos autores no aportan nada nuevo a la teoría de los pronombres. Lo que dicen sobre esta parte del discurso no se distingue, en lo fundamental, de lo que decían los gramáticos de siglos anteriores. Los verdaderos cambios no se producen hasta el siglo XVIII, como ya adelantábamos. 
En 1706, el abate Régnier-Desmarais, en su Traité de la langue françoise, propone un inventario de los pronombres en el que ya se pueden encontrar en germen las transformaciones que se manifestarán algunos decenios después. Por una parte, asistimos a una especie de erosión de la clase de los pronombres: algunos de ellos serán redistribuidos en otras categorías, especialmente en la de los artículos. En segundo lugar, percibimos ya una mayor profundización en la reflexión sobre la naturaleza de los pronombres, y particularmente sobre la de los personales.

En efecto, pronto surge la idea de que muchas palabras, consideradas hasta ese momento como pronombres, son en realidad determinantes, es decir, signos de naturaleza próxima a la de los artículos ${ }^{5}$. Estas ideas son adoptadas por la mayoría de los gramáticos de esta época: Beauzée, Condillac, Desttut de Tracy, etc. En todos ellos, el inventario de los pronombres tiende a reducirse y a limitarse a los personales.

Al mismo tiempo, los gramáticos empiezan a interrogarse sobre el estatus lógico de los pronombres. Una reflexión sobre este punto era tanto más necesaria cuanto que las definiciones habitualmente admitidas no eran satisfactorias. Así, por ejemplo, Arnauld y Lancelot (1660: 43-44) se contentaban con definir los pronombres como palabras inventadas con el único fin de evitar la repetición de los nombres. Estas justificaciones de la existencia de los pronombres basadas en la comodidad o el estilo no podían perdurar.

En su Grammaire françoise sur un plan nouveau, cuya primera edición data de 1709 , Buffier observa, a propósito de los pronombres, lo siguiente: "Tous les mots qui sont employez pour marquer simplement un sujet, dont on peut afirmer quelque chose, doivent être tenus pour des noms: ils répondent dans le langage à cette sorte de pensées, qu'on apelle "idées" dans la logique..." (pp.49-50).

Estas observaciones dan lugar a una cuestión delicada. Nadie pone en duda el hecho de que los nombres propiamente dichos expresen ideas, pero resulta difícil aceptar lo mismo para los pronombres. Es evidente que los nombres expresan ideas generales que resultan de "l'abstraction des qualités particulières aux individus" (Condillac 1776: 48), y que se encuentran, por tanto, asociados a conceptos que representan, no individuos u objetos determinados, sino clases de objetos o de individuos. Sin embargo, para los pronombres, la cuestión es más delicada, ya que, aunque compartan con los nombres el privilegio de poder ser sujeto de una proposición, y aún suponiendo que puedan expresar también una idea, ésta resulta problemática. Algunos gramáticos de esta época se plantearon ya el problema de la naturaleza paradógica de los pronombres personales, e intentaron encontrar la solución interrogándose sobre el sentido mismo del término persona.

Como ni Prisciano ni Donato se habían preocupado de precisar su significación, probablemente porque para ellos era evidente, los gramáticos del siglo XVIII buscan la

\footnotetext{
${ }^{5}$ Así, el abate Régnier (1706) señala el parentesco que existe entre un(e), por una parte, y tout, quelque, certain, etc. por otra (p.155). Du Marsais (1769) va más lejos aún: después de definir los artículos como "des prénoms ou adjectifs métaphysiques qui marquent, non des qualités physiques des objets, mais seulement des points de vue de l'esprit, ou des faces différentes sous lesquelles l'esprit considère le même mot" (p.347), confecciona una lista de artículos que engloba numerosos elementos considerados hasta entonces como pronombres. Así, junto al propio artículo, encontramos términos como tout, chaque, nul, aucun, quelque, certain, ce, cette, ces y los "nombres de número" (un, deux, trois,...).
} 
etimología de este término: la palabra PERSONA servía inicialmente para designar las máscaras que llevaban los actores de la Antigüedad, y a través de las cuales hacían oir su voz (PER-SONARE). Los pronombres personales son, pues, según Court de Gébelin (1774:41), "comme ces masques d'Arléquin ou de Pantalon qui sont portés par quiconque est chargé de jouer un de ces rôles, quoiqu'il ne soit ni Arléquin ni Pantalon”.

Por otra parte, se produce en esta época cierta vacilación en cuanto a la denominación exacta que conviene dar a los personales. Algunos los caracterizan como "adjectifs de personne", ya que parecen "ajouter aux vrais noms des idées une détermination qui leur manque" (Destutt de Tracy 1825: 55). Sin embargo, otros autores como Condillac (1776: 156) consideran je y tu como verdaderos sustantivos.

Estas divergencias de tratamiento se explican facilmente a partir de la noción de rôle y de la forma en que se concilia esta noción con la concepción que se tenía del signo lingüístico. Lo que caracteriza al signo lingüístico es que contiene una doble representación: por una parte, el vínculo que existe entre la palabra (el significante) y la idea (el significado), por otra, el que une la idea al objeto al que se aplica, es decir, al referente extralingüístico. En el caso de los pronombres, la primera relación es estable, ya que los "rôles" representados son siempre los mismos; pero la segunda no parece regida por ningún principio, puesto que los individuos designados no constituyen una clase definida por sus propiedades.

Si consideramos esta segunda relación, los pronombres pueden aparecer como adjetivos, en la medida en que expresan una calificación que no pertenece propiamente ni de manera permanente al objeto designado. Sin embargo, si consideramos la relación entre el significante y el concepto, asimilaríamos los pronombres a los sustantivos, porque representan, como ellos, "des idées isolées et désignées comme ayant dans notre esprit une existence propre et absolue" (Destutt de Tracy 1825: 55). De hecho, estos dos puntos de vista no son incompatibles, sino que definen el doble aspecto de la significación de los pronombres. En todo caso, para conciliarlos será necesario hallar una definición más precisa de la noción de rôle, y será N. Beauzée (1767) quien la encuentre.

Para captar mejor la originalidad de su teoría, recordemos brevemente los términos del problema:

1) En el esquema que aparece a continuación, hemos querido representar la doble relación palabra-idea e idea-objeto en los nombres. En efecto, los nombres comunes significan ideas, y esas ideas se presentan como la suma de un cierto número de rasgos a,b,c,... que definen la intensión de la idea $\mathrm{X}$, aplicable a los objetos $\mathrm{X}_{1}, \mathrm{X}_{2}, \mathrm{X}_{3}$,.. que tienen en común dichos rasgos: 
PALABRA

IDEA
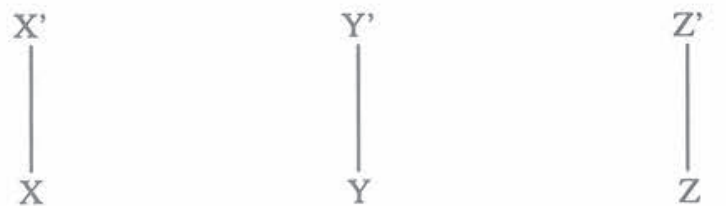

OBJETOS
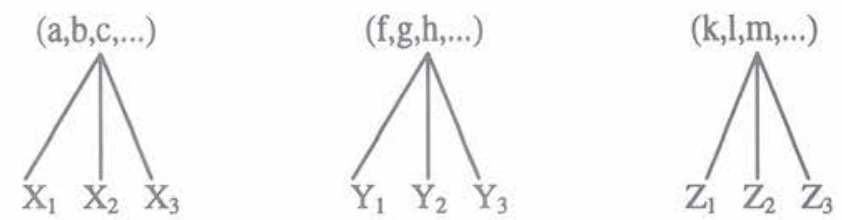

2) Estas mismas relaciones en los pronombres personales quedarían representadas como en este segundo esquema:

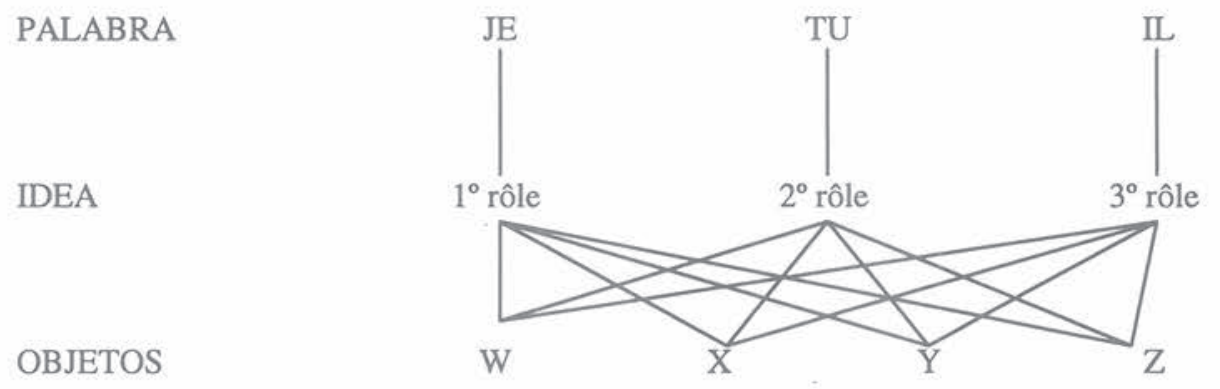

En efecto, como apunta Court de Gébelin (1774:41), los pronombres personales expresan los diferentes "rôles" que los hombres pueden asumir en los "tableaux de la Parole": "le premier rôle est sans contredit le rôle de celui qui parle (...), le second rôle sera rempli par ceux qui l'écoutent et auxquels il s'adresse; le troisième renfermera ceux dont il parle".

Como se puede apreciar en estos esquemas, la relación palabra-idea es la misma para nombres y pronombres. Por tanto, habrá que situarse en la relación idea-objeto para poder dar cuenta de lo que los diferencia. Y lo que los diferencia es justamente la naturaleza de la idea expresada: los nombres -afirma Beauzée (1767: t.I., 274)- "déterminent les êtres par l'idée de leur nature". Sin embargo, "ce n'est pas la même chose des pronoms -sigue diciendo este autor-, puisque le même pronom peut désigner des êtres de diverses natures; TU, par exemple, désigne un homme quand on adresse la parole à un homme; il désigne un cheval, un chien, un arbre, un ruisseau, le ciel, la terre, la république, un être abstrait, un être réel, la divinité même,(...); toutes les natures sont indifférentes à la signification de TU. Mais TU désigne toujours l'être auquel on adresse la parole, quelle qu'en soit la nature; JE désigne toujours l'être qui parle ou qui est censé parler; etc.". Y añade: "Nous voilà, si je ne me trompe, sur la 
bonne voie: les noms expriment des êtres déterminés, en les désignant par lidée de leur nature; les pronoms expriment des êtres déterminés, en les désignant par l'idée de leur personne. Ce mot PERSONNE, pour ôter lieu à toute équivoque, a besoin d'être expliqué. Il y a trois relations générales que peut avoir à l'acte de la parole le sujet de la proposition: car ou il prononce lui-même la proposition dont il est le sujet, ou la parole lui est adressée par un autre, ou il est simplement sujet sans prononcer le discours ni être apostrophé" (t.I., pp. 269-270).

A partir de ahí, parece que todo se clarifica. En efecto, como "le rôle est lui-même accidentel au sujet" (Beauzée 1767: t.I, 273), los pronombres pueden ser aplicados a seres de naturalezas diversas. El gran descubrimiento de Beauzée es haber comprendido que la "parole" es un acto y un acontecimiento singular. Podemos afirmar sin reservas que lo que él denomina "acte de la parole" coincide exactamente con lo que hoy día designamos con la misma expresión, o con lo que llamamos "enunciación". Este concepto intervendrá igualmente en su teoría de los tiempos verbales (Cfr. Beauzée 1767: t.I., 430-433).

Los análisis de este gramático son, sin lugar a dudas, modernos y muy próximos a los que se desarrollan actualmente. Pero su descubrimiento se produjo un poco tarde, en un momento en que la Gramática General estaba ya a punto de ser remplazada por la Gramática Histórica y Comparada, de manera que el pensamiento de Beauzée no tuvo tiempo de dar sus frutos. A pesar de ello, sus teorías llegaron a influir en algunos de los últimos grandes representantes de la Gramática General, que basaron su definición de los pronombres personales en el "acte de la parole" 6

A pesar del carácter extremadamente nuevo e incluso revolucionario de los análisis consagrados a las personas y a los tiempos verbales, la obra de Beauzée se muestra insuficiente en otros puntos: por ejemplo, decepciona un tanto el hecho de que no se señale la evidente relación de otros signos, tales como ciertos adverbios de tiempo -hier, demain, aujourd'hui-, con el "acte de la parole". Para Beauzée, estos términos son simplemente nombres, puesto que pueden ser sujeto de una proposición (Beauzée 1767: t.I, 558-559).

Del mismo modo, resulta insuficiente la definición de la tercera persona, que es situada en el mismo plano que la primera y la segunda. Es cierto que ya algunos autores anteriores a Beauzée, así como algunos de sus contemporáneos, habían subrayado la diferencia existente entre je/tu, por un lado, e $i l$, por otro ${ }^{7}$. De todos modos, estas distinciones se basaban en consideraciones sintácticas: diferenciaban la tercera persona de la primera y segunda porque no puede usarse en las mismas condiciones que ellas, y debe apoyarse en un término ya mencionado. Hoy día, la distinción viene motivada, ante todo, por consideraciones pragmáticas: jeltu son solidarios en el seno de la "réalité humaine du dialogue" (Benveniste 1966: 232). Esto que nos parece hoy tan evidente no es tenido en cuenta en las teorías

\footnotetext{
${ }^{6}$ Es el caso de l'Abbé Sicard (1808, t.I.: 185-190) o de Destutt de Tracy (1825), quien escribe: "JE est successivement le nom de toutes les personnes qui parlent; TU, celui de toutes les personnes à qui on parle, et IL celui de toutes les personnes et de toutes les choses dont on parle. De plus, ces mots ne représentent point proprement, ne peignent point toutes ces personnes et ces choses; ils ne nous apprennent rien d'elles que leur rapport avec l'acte de la parole, et c'est même pour cela qu'ils conviennent à toutes celles pour qui ce rapport est le même"(p. 53).

${ }^{7}$ Cfr. Condillac 1776: 156-157; F. Thurot en una de las notas de su traducción de la obra de Harris (1972 (1796): 77); y antes que ellos, Dangeau (Citado por A. Joly en su introducción al Hermès de Harris (1972 (1796): 79-80).
} 
lingüísticas de la Época Clásica. Beauzée no establece ningún tipo de jerarquía entre las personas. Es el "acte de la parole" el que considera soberano, no a la persona que lo realiza. Para él, la "parole" no está subordinada a la persona que habla. El discurso que la Gramática General tiene por objeto es un discurso sin sujeto. La noción misma de subjetividad no existe todavía, es una creación del siglo XIX. Lejos de ser concebido como el centro de un sistema de coordenadas comparable a la ego-hic-nunc-origo de Karl Bühler (1967 (1934)), je no posee, en la teoría de Beauzée, ningún estatus particular. El elemento central no es ego, sino la producción del discurso.

Sin duda alguna, esta última noción constituye la aportación más importante de Beauzée. Pero, si pudo crear este concepto, fue porque en la Época Clásica el objeto de la gramática había cambiado. Ya no se trataba de la oratio concebida como discurso efectuado, sino de "l'énonciation de la pensée par le secours de la parole prononcée ou écrite" (Beauzée 1767, t.I.: IX), es decir, una operación y no su resultado. Esta concepción da lugar lógicamente a la distinción que hace Destutt de Tracy (1825:276) entre lenguaje y discurso: "Tout système de signes est un langage; toute émission de signes est un discours", distinción que anuncia claramente la que establecemos hoy día entre lengua y habla.

\section{LA GRAMÁTICA HISTÓRICA Y LA APARICIÓN DEL CONCEPTO DE SUBJETIVIDAD.}

Entre las transformaciones que han marcado el advenimiento de la Gramática Histórica y Comparada, hay dos que merecen especialmente nuestra atención por la incidencia que han tenido en la teoría de los pronombres y en la noción de deíxis:

1) Las raíces se distribuyen en dos grandes categorías: las raíces verbales u "objetivas" y las raíces pronominales o "subjetivas". Las primeras habrían dado lugar a los verbos y a los nombres -adjetivos o sustantivos-; las segundas estarían presentes tanto en los pronombres propiamente dichos, como en ciertas preposiciones, conjunciones, partículas, etc. Estas raíces pronominales cobran su valor de la relación que mantienen con el sujeto. De esta manera, los pronombres, que hasta ese momento habían permanecido íntimamente ligados al nombre, se verán incluidos en una nueva categoría de la que forman parte elementos pertenecientes a las más diversas clases de palabras.

2) Los pronombres personales -los elementos pronominales por excelencia- son objeto de una especial atención, y la manera de concebirlos se renueva por completo. Lo esencial no es ya, como en la Época Clásica, la relación de las personas con el acto de enunciación, sino la relación del sujeto con el otro y con el mundo.

En efecto, por una parte, las filiaciones históricas, los parentescos de raíces, llegan a ser más importantes que todas las afinidades semánticas o funcionales. Es lo que lleva a descubrir una característica pronominal en signos tan diferentes. En cuanto a la utilización del término sujeto en un sentido que no guarda ninguna relación estricta con una determinada función gramatical, se explica por la trasposición al dominio de la ciencia del lenguaje de un cambio que ha afectado al saber general a principios del XIX: la distinción entre "sujet connaissant" y "objet de la connaissance". Así pues, estas transformaciones se explican en base a la 
confluencia de dos acontecimientos: por una parte, una innovación propia de la ciencia del lenguaje -el concepto de raíz-, y por otra, la "importación" de conceptos forjados por la teoría del conocimiento.

Bopp (1875), en su Gramática Comparada, consagra interesantes análisis a los pronombres personales en el conjunto de las lenguas indoeuropeas. El hecho más destacable, común a todas estas lenguas, es que el pronombre de primera persona del singular y del plural tienen raíces diferentes. En los nombres, sin embargo, el paso del singular al plural se marca simplemente por la adición de una desinencia. Esto se explica, según Bopp, por la diferencia de naturaleza de los nombres y de los pronombres. LEONES remite a una pluralidad de individuos que poseen, todos y cada uno de ellos, las cualidades expresadas por la palabra LEO. Lo mismo puede aplicarse a ils, que multiplica la noción expresada por il. Sin embargo, no existe más que un yo, por lo que nous expresa una idea que comprende al mismo tiempo el yo y un número indeterminado de individuos que no son yo. Nous no es por tanto el plural de je/moi, como LEONES es el plural de LEO; es decir, que no está sometido a las mismas reglas de pluralización que los nombres (t.II: § 331, 263-64).

Bopp encuentra en sus investigaciones la confirmación de su razonamiento. El pronombre sánscrito de primera persona del plural es la combinación de dos raíces: -a, que figura también en la forma del singular a-há-m, y -smê que significa "ellos", de manera que a-smê quiere decir realmente "yo y ellos". De la mịsma manera, yu-smê ("vosotros") significaría "tú y ellos". En efecto, "la réunion de l'élément singulier 'moi, toi' et de l'élément pluriel 'eux', l'un représenté par a et yu, l'autre par smê, aurait donc servi à marquer les idées complexes 'nous' et 'vous', qui ne pouvaient recevoir une expression plus naturelle, plus claire et plus complète" (t.II: $\S 333$, pp.265-266).

Aunque el concepto de sujeto no sea siempre mencionado explícitamente, está presente de manera implícita en las reflexiones de todos los gramáticos de esta época. En efecto, el carácter irreductible del sujeto y su unicidad es lo que garantiza los fundamentos de la distinción entre raíces verbales y pronominales. Lo que caracteriza a las primeras es que tienen valor descriptivo, denotan movimientos, cualidades u objetos; sin embargo, el único rasgo que tienen en común las segundas es el hecho de recibir toda su significación de lo que Humboldt (1963 (1836):484) llama el "sentimiento inmediato de la personalidad" ("das unmittelbare Gefühl der Persönlichkeit"), que reside en el sujeto. En efecto, estas raíces pronominales cobrarían todo su valor de la relación que mantienen con el sujeto, concebido como una instancia única e indivisa que garantiza la unidad de un conjunto heterogéneo de elementos. Así pues, será necesaria una nueva teoría de los pronombres personales que sirva de fundamento a la gran división de las raíces.

Será Humboldt, contemporáneo de Bopp y, para muchos, el más ilustre representante de la Gramática Histórica, el que presente de manera más clara el sentimiento del yo (ichgefühl) como origen y fundamento de las raíces pronominales (Ibídem:482-484). Las raíces descriptivas son llamadas "objetivas" y las que remiten de alguna manera al sujeto son calificadas con el término de "subjetivas". Es evidente que el fundamento de esta distinción implica una caracterización precisa de la noción de persona. 
Se parte del sentimiento inmediato que tiene el sujeto hablante de sư propia existencia frente a la naturaleza. Esta conciencia no es el fruto de una reflexión. El hombre intuye inmediatamente su existencia individual, y sería inconcebible que hablase de sí mismo como de un ser extraño. Incluso antes de haber asimilado el uso del yo, los niños se conciben ya como diferentes del mundo que los rodea. Y ese "sentimiento del yo" (Ichgefühl) es el elemento primordial a partir del cual se construye el sistema de las personas.

Frente al yo está el tú que mantiene con la primera persona una doble relación: por una parte, el tú forma parte del NO-YO, y por otra, guarda una estrecha relación con el YO, pues los dos se oponen a todo lo que no sea ellos, en tanto en cuanto constituyen la comunidad de los seres que piensan, hablan y actúan (“der Kreis der Fühlenden und Sprechenden”). La significación del tú implica por tanto dos cosas: a) un sentimiento de interioridad, porque en presencia de su interlocutor, el sujeto hablante siente que está de alguna manera frente a otro "yo"; b) y una relación de exterioridad, puesto que, a pesar de todo, el tú es aprehendido por el yo como "otro", como diferente. En cuanto a la tercera persona, se extiende a todos los seres y su relación con el yo es puramente externa.

Debemos, por tanto, concebir el sistema de las personas como estructurado según una doble oposición: una primera que se establece entre el YO y el NO-YO, y una segunda que separa la esfera del YO y del TÚ del resto. Según Humboldt, si el tú ocupa una posición privilegiada en el seno del NO-YO, no es sólo porque el locutor elige libremente aquél al que se dirige, sino también porque la existencia del interlocutor es indispensable para el ejercicio del lenguaje. La tercera persona engloba todo lo que es exterior al espacio compartido por el yo y por el tú, pudiendo representar también a los seres inanimados (Ibídem: 203).

A pesar de lo que pueda sugerir, esta concepción no es idéntica a la de E. Benveniste (1966), porque la arquitectura del sistema está basada, no en las relaciones engendradas por el "acte de la parole", sino en las que mantienen las personas entre sí. Las personas son consideradas, por tanto, como los vértices de un sistema triangular, como elementos que se definen recíprocamente, de manera que el acto de enunciación pierde protagonismo. El yo se convierte en el punto fijo que asegura la cohesión del conjunto. La noción de enunciación, aunque no es explícitamente rechazada, deja de intervenir. El centro de referencia no es ya el acto de habla, sino el sujeto hablante. En efecto, no aparece nunca la expresión "acte de la parole", y las relaciones que definen a los pronombres son relaciones con el locutor, no con la enunciación. A partir de este momento, el concepto clave es, pues, el de sujeto. La noción de persona cobra sentido en relación con él, y de él extraen todo su contenido las raíces pronominales o subjetivas.

Los Formwörter, término que designa las palabras derivadas de raíces "subjetivas", se oponen a los Stoffwörter, derivados de raíces "objetivas", y se encuentran en las más diversas clases de palabras, porque el concepto de raíz trasciende el de clase de palabra. Por ello, entre los Formwörter encontramos preposiciones, conjunciones, adverbios, morfemas de flexión, determinantes y, naturalamente, pronombres. La creación de una categoría transversal que trasciende las tradicionales distinciones entre las diferentes partes del discurso, es indudablemente un acontecimiento muy importante. No hay que olvidar que, desde los orígenes de la gramática, los pronombres habían estado siempre relacionados con los 
nombres. Gracias a la conjunción del concepto de sujeto y de la noción de raíz, pudieron descubrirse otras afinidades.

Desde esta perspectiva, el artículo de Brugmann sobre los demostrativos de las lenguas indoeuropeas -Die Demonstrativpronomina der indogermanishen Sprachen-, citado en todos los trabajos sobre la deíxis, aparece como una obra de síntesis más que como una contribución innovadora. Lo que distingue la posición de Brugmann de la de otros gramáticos de la misma época es que este autor concede un lugar a parte a los pronombres personales, y reserva la apelación de deícticos a los pronombres-adjetivos demostrativos, a los adverbios de lugar hier, da, dort (aquí, ahí, allî), y a ciertos adverbios de tiempo como heute (hoy). Sin embargo, en su concepción de la deíxis, la noción de sujeto sigue ocupando un lugar central (Cfr. Brugmann/Delbrück 1911: 310).

Las dos contribuciones esenciales de la Gramática Histórica son, pues, el concepto de subjetividad y la creación de una categoría transversal que engloba tanto a pronombres como a adverbios o a determinantes. A partir de ese momento, resulta posible hablar de la deíxis como de un fenómeno lingüístico general, que no se adhiere a una determinada clase de palabras, sino que se manifiesta a través de las partes del discurso más diversas.

Sin embargo, la descripción de las innovaciones del siglo XIX estaría incompleta si no evocásemos también la incidencia indirecta que tuvo sobre la teoría de los pronombres y sobre la concepción de todos los elementos deícticos, la aparición de una lógica que difiere profundamente de la de la Época Clásica. Naturalmente, la influencia de esta nueva disciplina sobre la lingüística es bastante indirecta. La formalización no hace aún su aparición en la ciencia del lenguaje, pero es probable que las exigencias de la formalización hayan conducido a los filósofos e, indirectamente, a los lingüistas a interrogarse de una manera nueva sobre la naturaleza de los pronombres y de los Formwörter en general.

\section{APORTACIONES DE LA LÓGICA. REHABILITACIÓN DEL CONCEPTO DE ENUNCIACIÓN.}

En efecto, la caracterización de los Formwörter no deja de presentar dificultades, cuando se intenta proponer una definición precisa de ellos. H. Paul (1886) percibió esta dificultad e intentó resolverla.

En primer lugar, propone distinguir entre la significación ocasional o individual de los signos y su significación habitual o general. La significación habitual de un signo es todo el contenido de representación al que está asociado dicho signo en el espíritu del hablante. Este contenido es el que posee un signo antes de ser utilizado en una situación concreta, es decir antes de su actualización en el discurso. El significado ocasional es el que toma un signo cuando es aplicado a un objeto particular. El uso de un signo en situación tiene por efecto enriquecer su intensión y restringir su extensión. Según Paul, la significación general de un signo es siempre abstracta; para que se concrete, ha de ser aplicado a una magnitud determinada por sus coordenadas espacio-temporales. Esta magnitud no tiene por qué ser necesariamente un objeto palpable, puede tratarse también de una cualidad o de una acción. Su carácter concreto procede esencialmente de su individualización espacio-temporal. 
Sin embargo, un cierto número de signos se adecúan mal a esta distinción, ya que no poseen un contenido determinado, y no reciben uno hasta ser aplicados a una situación concreta (Cfr. Paul 1886:67). En efecto, los pronombres personales, posesivos y demostrativos, y los adverbios demostrativos tienen la particularidad de no tener, al contrario que la mayoría de los signos, una significación que permanezca constante al margen de todas las aplicaciones particulares. Su significación es, por tanto, dependiente de sus condiciones concretas de uso. El problema que plantean estos signos no es resuelto por Paul. La paradoja no es superada, pero la cuestión es tratada en términos más precisos que en otros lingüistas.

Sus observaciones atrajeron la atención de E. Husserl, que en sus Investigaciones Lógicas (1967 (1900)) consagra a las expresiones citadas por Paul extensos análisis. Las califica de "esencialmente subjetivas y ocasionales" (t.I, p.374), lo que nos hace pensar que había leido la obra de Paul (Prinzipien der Sprachgeschichte). Husserl caracteriza las expresiones objetivas por su propiedad de poder ser comprendidas sin referencia alguna a las condiciones concretas en las que son usadas. Las ocasionales, al contrario, no tienen esta virtud: el oyente sólo puede asociarlas a una representación si las pone en relación con las circunstancias concretas de la enunciación.

Evidentemente, si bien es cierto que el concepto de subjetividad y la noción de raíz permitieron trascender la noción de clase de palabra, ejerciendo así un papel positivo, no podemos obviar el aspecto negativo de su influencia. En efecto, para una descripción exacta de estos términos ocasionales, es preciso recurrir al concepto de "acte de la parole". No negamos que haya de tenerse en cuenta la actividad específica del locutor, pero tampoco puede faltar la idea de la enunciación, concebida como acontecimiento singular. Esta idea permitiría comprender que la significación de je (moi) es estable, porque expresa siempre el mismo "rôle", es decir, la misma relación con el "acte de la parole", y que si designa cada vez a un ser diferente, es porque cada vez que es enunciado, la localización se hace con relación a un acontecimiento diferente. Es evidente, por ejemplo, que no podemos descifrar la significación de hier o demain si partimos simplemente de la idea de que están relacionados con el sujeto. El punto de referencia a partir del cual se definen es el momento de la producción del discurso y no la persona que habla.

Si bien es cierto que, en un principio, la reflexión lógica se vió dificultada por la inadecuación de los conceptos que la lingüística había puesto a su disposición, sin embargo, más tarde confirmó algunos de los resultados más interesantes de la investigación gramatical del siglo XIX y permitió superar ciertos obstáculos relacionados con algunos de los conceptos fundamentales de esta investigación.

En primer lugar, los trabajos de los lógicos confirman que el parentesco de los signos derivados de raíces pronominales no es simplemente histórico, sino que se manifiesta con claridad también en las propiedades lógicas de estos signos. Así, en Der Gedanke. Eine logische Untersuchung, Frege (1966 (1918-19)) pone de manifiesto el rasgo común a los tiempos verbales, a los adverbios de tiempo como hier o aujourd'hui, a los adverbios de lugar como ici o là, y a los pronombres personales (pp.37-38). Cuando una frase contiene un pronombre personal o un adverbio de este tipo, no podemos extraer un pensamiento completo, es decir, una proposición, a no ser que se disponga de ciertas informaciones sobre las 
condiciones en las que la frase ha sido enunciada. Aunque Frege se preocupa más de poner de manifiesto las particularidades lógicas de estos signos que de encontrar una definición para ellos, observamos que hace intervenir el concepto de enunciación (das Sprechen) que buscábamos en vano en los textos anteriores.

Tras él, encontramos aún dudas y confusiones entre la noción de sujeto y la de acto de habla. Cuando B. Russel (1943) crea la expresión egocentric particulars, sufre la lejana influencia del siglo XIX. No se entiende muy bien por qué estos signos son considerados egocéntricos. A este respecto, J.C. Pariente (1973:88) observa lo siguiente: “...ici n'est pas l'endroit où $\mathbf{J E}$ parle, mais celui où je PARLE, c'est, sans ambiguïté, celui où un locuteur quelconque, toi ou moi, prononce ces phonèmes...". Y añade: "C'est pourquoi nous n'appellerions peut-être pas, comme le fait Russel, les indicateurs "egocentric particulars": ils ne se rapportent pas directement à l'EGO, mais au message dans lequel ils apparaissent" (p.88, nota 5).

La confusión se disipa definitivamente con la publicación de Elements of Simbolic Logic de Reichenbach -cuya primera edición data de 1947- con la introducción del concepto de token-reflexive words: "It is easily seen that all these words can be defined in terms of the phrase 'this token'. The word 'T', for instance, means the same as 'the person who utters this token'; 'now' means the same as 'the time at which this token is uttered' ..." (Reichenbach 1966 (1947): 284).

Al utilizar el concepto de token, Reichenbach pone fin a las dudas que habían caracterizado el pensamiento de sus predecesores, $\mathrm{y}$, al mismo tiempo, conecta, tras dos siglos de intervalo, con el pensamiento de Beauzée. En realidad, Reichenbach no menciona la noción de acto de habla, pero lo que denomina "token" es, de alguna manera, el reverso de la medalla. Es la ocurrencia singular de una frase, un enunciado caracterizado por sus coordenadas espacio-temporales, es decir, el resultado de lo que Beauzée denominaba "l'acte de la parole". La producción del discurso, concebida como acontecimiento singular, y el "token", considerado como un ejemplar único de mensaje, constituyen las dos caras de una misma moneda, ya que un acto de habla sólo puede ser aprehendido en su singularidad si, además de saberse dónde y cuándo ha sido realizado, puede identificarse la materia lingüística que ha tenido por objeto; y un enunciado sólo puede ser realmente definido si podemos no sólo describir la frase de la que él es una realización particular, sino también datar y localizar el proceso que lo ha engendrado. Ambos conceptos no se oponen, se complementan.

Así pues, si el descubrimiento del fenómeno de la enunciación se lo debemos a un gramático, Beauzée, su redescubrimiento ha sido realizado por un lógico, Reichenbach. Creemos, en efecto, que la rehabilitación del concepto de enunciación en lingüística ha sido muy posiblemente consecuencia directa o indirecta de la publicación de la obra de este autor. Es cierto que el primer artículo de Benveniste sobre la noción de persona, "Structure des relations de personne dans le verbe" (recogido en Benveniste 1966: 225-236), data de 1946, pero el concepto de "acte de la parole" no aparece aún de manera clara. Naturalmente, no pretendemos, al recordar estos detalles cronológicos, atribuir o quitar méritos a nadie, sino únicamente subrayar los fenómenos de interacción que se han producido entre la lógica y la investigación lingüística. En efecto, si fue la Gramática Histórica, sin lugar a dudas, la que 
creó la categoría de los deícticos, es muy probable que los lingüistas reconocieran el vínculo fundamental que une esta clase transversal a la enunciación gracias a la influencia de los trabajos de los lógicos.

\section{CONCLUSIÓN.}

Tras este recorrido histórico, llegamos a las siguientes conclusiones:

1. Hasta finales del Renacimiento, el concepto de mostración (demonstratio, deíxis) se ha visto prácticamente identificado con una clase de palabras: los pronombres. Eran considerados demostrativos tanto los pronombres personales como los verdaderos demostrativos -según la terminología más extendida-, es decir, hic, iste, ille. Al mismo tiempo, el contenido del término demonstratio permanecía impreciso, admitiéndose, por regla general, que este término hablaba por sí solo y que no era, por tanto, necesario insistir en él.

2. Sin embargo, en la Época Clásica, la teoría de Beauzée hizo saltar por los aires la categoría tradicional de los demostrativos, al permitir caracterizar de manera precisa los pronombres personales, gracias al concepto de acte de la parole. En efecto, je, tu, il dejan de formar parte de esta categoría. A pesar de ello, el concepto de mostración no es precisado y permanece independiente del de acto de habla.

3. Con la Gramática Histórica, la noción de enunciación cae en el olvido, pero, simultáneamente, por el efecto conjunto de las nociones de sujeto y de raíz, los pronombres se integran en un vasto conjunto de elementos pertenecientes a las clases de palabras más diversas, y agrupados en base a su origen común: las raíces pronominales, cuya característica primordial es la de expresar una relación con el sujeto. De esta manera, aunque el término deíxis no aparece hasta comienzos de nuestro siglo con Brugmann, podemos afirmar, sin embargo, que la categoría de los deícticos fue creada en el siglo XIX, ya que fue entonces cuando se reunió, bajo una única denominación -la de Formwort-, tanto a los pronombres personales o demostrativos, como a adverbios de tiempo y lugar tales como aujourd'hui, là, ici, etc.

4. De todos modos, y sin ignorar los méritos considerables de la Gramática Histórica, hay que reconocer que la categoría de los deícticos se constituyó a costa de ciertas imprecisiones y ambigüedades y, si bien es cierto que la rehabilitación, por parte de los lógicos, del concepto de enunciación ha permitido disipar algunas de las confusiones engendradas por el pensamiento de los gramáticos del siglo XIX, otras han persistido hasta nuestros días, como ciertamente podemos comprobar en algunos trabajos contemporáneos. 


\section{BIBLIOGRAFÍA}

A. ARNAULD \& C. LANCELOT (1969 (1660)): Grammaire générale et raisonnée, Paris: Republications Paulet.

N. BEAUZÉE (1767): Grammaire Générale, 2 vol., Paris: J. Barbou.

E. BENVENISTE (1966): Problèmes de Linguistique Générale I, Paris: Gallimard.

F. BOPP (1875 (1866)): Grammaire comparée des langues indo-européennes, $2^{\circ}$ ed., 5 vol., traducción e introducción de M. Bréal, Paris: Imprimerie Impériale.

K. BRUGMANN (1904): "Die Demonstrativpronomina der indogermanischen Sprachen", Abhandlungen der Sächsischen Gesellschaft der Wissenschaften, 22, 6, 1-144.

K. BRUGMANN \& B. DELBRÜCK (1911): Grundiss der Vergleichenden Grammatik der indogermanischen Sprachen, $2^{\circ}$ ed., Strassburg.

BUFFIER (1732 (1709)): Grammaire françoise sur un plan nouveau, Paris: Marc Bordelet.

K. BÜHLER (1967 (1934): Teoría del lenguaje, $3^{\circ}$ ed., Madrid: Revista de Occidente.

P. CARBONERO (1979): Deíxis espacial y temporal en el sistema lingüístico, Sevilla: Universidad de Sevilla.

CONDILLAC (1776): Grammaire (tomo I del Cours d'étude pour l'instruction du Prince de Parme), Londres: Libraires François.

COURT DE GÉBELIN (1774): Monde primitif, analysé et comparé avec le monde moderne considéré dans l'histoire naturelle de la parole ou grammaire universelle et comparative (forma parte de un conjunto de 9 volúmenes publicados bajo el título Monde primitif... y no numerados. Paris: 1773-1782).

DESTUTT DE TRACY (1825): Eléments d'Idéologie. Seconde partie: Grammaire, Paris: Mme Lévi, Libraire.

DONATO: De partibus orationis ars minor/Ars grammatica, in Grammatici Latini, t. IV, ed. H. Keil, Hildesheim: Georg Olms, 1961.

J. C. ESCALÍGERO (1540): De causis linguae latinae, Lugduni.

R. ESCAVY ZAMORA (1987): El pronombre. Categorías y funciones pronominales en la teoría gramatical, Murcia: Servicio de Publicaciones de la Universidad.

G. FREGE (1966 (1918-19)): Der Gedanke. Eine logische Untersuchung (tomo I de Logische Untersuchungen), Göttingen: Vandenhoeck \& Ruprecht.

J. HARRIS (1972 (1751)): Hermès ou Recherches Philosophiques sur la Grammaire Universelle, según la traducción de François Thurot (Paris: Messidor, 1796), introducción de A. Joly, Genève: Droz.

W. von HUMBOLDT (1963 (1836)): Schriften zur Sprachphilosophie, t.III, ed. A. Flitner \& K. Giel, Stuttgart: J.G. Gotta'sche Buchhandlung.

E. HUSSERL (1967 (1900)): Investigaciones Lógicas, 2 vol., $2^{\circ}$ ed., Madrid: Revista de Occidente. 
C.Ch. Du MARSAIS (1769): Logique et Principes de Grammaire, Paris: Briasson, Le Breton, Herissant fils.

J.C. PARIENTE (1973): Le langage et l'individuel, Paris: Armand Colin.

H. PAUL (1886): Prinzipien der Sprachgeschichte, $2^{\mathrm{a}}$ ed., Halle.

PRISCIANO: Institutionum Grammaticarum, in Grammatici Latini, t.II-III, ed. H. Keil, Hildesheim: Georg Olms, 1961.

J.S. RÉGNIER-DESMARAIS (1973 (1706)): Traité de la grammaire française, Genève: Slatkine Reprints.

H. REICHENBACH (1966 (1947)): Elements of Symbolic Logic, New York: The Free Press.

B. RUSSEL (1943): An Inquiry into Meaning and Truth, $2^{\mathrm{a}} \mathrm{ed}$., London.

F. SÁNCHEZ DE LAS BROZAS, EL BROCENSE (1976 (1587): Minerva seu de causis linguae latinae. Madrid: Cátedra.

SICARD (1808): Éléments de grammaire générale appliqués à la langue française, $3^{\mathrm{a}}$ ed., Paris.

M.T. VARRÓN: De lingua latina, edición bilingüe latín-inglés, traducción de R.G. Kent, Coll. "The Loeb Classical Library", Harvard: Heinemann ltd., 1967. 